\title{
Separation of RNA according to Size: Electrophoresis of RNA through Denaturing Urea Polyacrylamide Gels
}

\author{
Michael R. Green and Joseph Sambrook
}

Thin (0.4-1.5 mm) polyacrylamide-urea gels provide high resolution of RNAs up to $1000 \mathrm{nt}$ in size and are capable of resolving single-stranded fragments of RNA that differ in length by as little as $1 \mathrm{nt}$. The polyacrylamide gel is cast between two glass plates that are separated by two thin Teflon or nylon spacers. A so-called shark's tooth comb or, less frequently, a standard slotted comb forms the sample wells into which the RNA samples are loaded before electrophoresis. In contrast to electrophoresis using agarose gels, which occurs while the gel is horizontal, polyacrylamide gels are run while in the vertical position. Gels are also typically run at $45^{\circ} \mathrm{C}-55^{\circ} \mathrm{C}$, which is the melting temperature of RNA, and in the presence of 6-8 $\mathrm{m}$ urea. The gel recipe and protocol presented here for $8 \mathrm{~m}$ urea/TBE polyacrylamide gels can be used for a variety of applications including mapping RNA with nuclease S1, ribonuclease protection assay, or analysis of RNA by primer extension.

It is essential that you consult the appropriate Material Safety Data Sheets and your institution's Environmental Health and Safety Office for proper handling of equipment and hazardous materials used in this protocol.

RECIPES: Please see the end of this protocol for recipes indicated by $<R>$. Additional recipes can be found online at http://cshprotocols.cshlp.org/site/recipes.

Reagents

Acrylamide solution $(40 \%, \mathrm{w} / \mathrm{v})(38 \%, \mathrm{w} / \mathrm{v}$ acrylamide; $2 \%, \mathrm{w} / \mathrm{v}$ bisacrylamide dissolved in water) Filter through a 0.2-mm filter, and store in dark glass at room temperature.

Because cheaper grades of acrylamide often contain contaminants, always use sequencing grade reagents. Acrylamide and bisacrylamide are slowly deaminated to acrylic acid in a reaction that is catalyzed by light. It is therefore necessary to store the solution in a dark bottle.

Alternatively, ready-to-use solutions of acrylamide/bisacrylamide 19:1 (40\%,w/v) are commercially available (e.g., Ambion, Bio-Rad, Sigma-Aldrich). Although somewhat expensive, the ready-to-use form reduces the dust, inhalation, and contact hazards associated with weighing acrylamide and bisacrylamide powders and preparation of the solutions.

Ammonium persulfate $(10 \%, \mathrm{w} / \mathrm{v})$ in water

Dissolve $1 \mathrm{~g}$ of ammonium persulfate in $10 \mathrm{~mL}$ of water. This reagent will keep for a few weeks at $4^{\circ} \mathrm{C}$. Alternatively, it can be stored at $-20^{\circ} \mathrm{C}$ in small aliquots. This solution should be relatively fresh; old ammonium persulfate solutions may not have the catalytic power to drive the polymerization reaction to completion.

Deionized water

From the Molecular Cloning collection, edited by Michael R. Green and Joseph Sambrook.

(C) 2021 Cold Spring Harbor Laboratory Press

Cite this protocol as Cold Spring Harb Protoc; doi:10.1101/pdb.prot101766 
M.R. Green and J. Sambrook

Detergent, household washing

Ethanol

Formamide loading buffer for RNA gels $<\mathrm{R}>$

Potassium hydroxide/methanol solution

The solution can be used to remove old silanizing reagent from glass plates. To prepare, dissolve $5 \mathrm{~g}$ of $\mathrm{KOH}$ pellets in $100 \mathrm{~mL}$ of methanol. Store the solution at room temperature in a tightly capped glass bottle.

RNA sample(s) for analysis

Samples of total or poly $(A)^{+}$RNA should consist of up to $20 \mu \mathrm{g}$ of RNA in a volume of $1-2 \mu \mathrm{L}$.

RNA size markers

We therefore recommend using RNA ladders (e.g., from Life Technologies) that contain RNAs of 9.49, 7.46, 4.40, $2.37,1.35$, and $0.24 \mathrm{~kb}$ in length. This allows the markers to be used as sentinels to detect RNase contamination or other problems that may occur during electrophoresis.

\section{Silanizing solution}

The traditional silanizing fluids (e.g., Sigmacote from Sigma-Aldrich, Repelcote from BDH, and Repel-Silane from GE Healthcare) contain dichlorodimethylsilane, which is toxic, volatile, and highly flammable. In recent years, nontoxic alternatives have become available, including Gel Slick (FMC Bioproducts), Rain-X (Unelko), and Acrylease (Stratagene).

TBE buffer $(10 \times, \mathrm{pH} 8.3)<\mathrm{R}>$

TBE is used at a working strength of $1 \times$ for polyacrylamide gel electrophoresis. This $1 \times$ concentration is twice the strength usually used for agarose gel electrophoresis. The buffer reservoirs of the vertical tanks used for polyacrylamide gel electrophoresis are fairly small, and the amount of electric current passed through them can be considerable. Use of the $1 \times T B E$ concentration provides the necessary buffering power. The $\mathrm{pH}$ of the buffer should be 8.3. It is generally not necessary to adjust the $\mathrm{pH}$; however, the $\mathrm{pH}$ of each new batch of $10 \times \mathrm{TBE}$ stock must be carefully checked.

Use the same stock of $10 \times$ TBE to prepare both the gel and the running buffers. Small differences in ionic strength or $\mathrm{pH}$ produce buffer fronts that can greatly distort the migration of the DNAs.

TEMED ( $N, N, N^{\prime}, N^{\prime}$-tetramethylethylene diamine)

Electrophoresis-grade TEMED is sold by many manufacturers including Sigma-Aldrich and Bio-Rad. TEMED is hygroscopic and should be stored in a tightly sealed bottle at $4^{\circ} \mathrm{C}$. TEMED is used as an adjunct catalyst for the polymerization of acrylamide.

Urea, solid

It is best to purchase sequencing or ultrapure grade.

Equipment

Bulldog binder clips ( $5 \mathrm{~cm}$ in length; five to seven per gel)

These all-metal butterfly clips are sturdier than plastic binder clips.

Gel-drying racks

Although not essential, gel-drying racks are certainly convenient for drying and storing glass plates used for polyacrylamide gel electrophoresis. These racks are available from several manufacturers including BioWhittaker.

Gel-sealing tape

For example, 3M Scotch Stretchable Tape (Lab Safety Supply, Janesville, Wisconsin), 3M Scotch Yellow Electrical Tape \#56 (Life Technologies), or 3M Scotch Polytetrafluoroethylene (PFTE) extruded film tape. For a discussion of the usefulness of various types of tape and other methods of sealing gel plates, see Hengen (1996).

Glass plates (matched pair)

The rectangular plates are made from nontempered glass, with one plate 3.5-4.0 cm longer than the other or with one plate notched. Glass is a liquid, and thus plates become deformed during use. To reduce the possibility of leaks and cracking, it is best to keep sequencing plates in matched pairs and to use the plates specified by the manufacturer of the sequencing gel tanks.

Gloves (talc-free, disposable rubber or PVC)

Petroleum jelly (e.g., Vaseline) (optional; see Step 5)

Power supply capable of wattage control 
Protective bench paper

Plastic-backed paper (Kaydry Lab Cover from Fisher Scientific) or Benchkote

Shark's tooth comb (0.4-mm thick, with 32, 64, or 96 teeth, depending on the capacity of the gel apparatus)

Spacers (two per gel, either constant thickness or wedge shaped)

Spacers are made of thin (0.4-1.5 mm), flexible plastic or Teflon (Sanger and Coulson 1978) and are used to keep the glass plates apart. A watertight seal is formed between the plates and spacers so that the unpolymerized gel solution does not leak out when the gel is cast.

Wedge-shaped spacers are used to produce gels that are thicker at the bottom than at the top. During electrophoresis, the increased cross sectional area generates field-strength gradients, resulting in sharpening of bands and a more uniform spacing of bands over the length of the gel (Ansorge and Labeit 1984; Olsson et al. 1984). Wedge-shaped gels are recommended when the goal is to increase the read-length of the gel but are not necessarily beneficial when the aim is to resolve compressions or to maximize resolution of a particular region of sequence. Although wedge-shaped gels may overcome band spacing problems, they are difficult to pour and often crack following drying.

Syringe (60 cc) (optional; see Step 12)

Vertical electrophoresis tank

\section{METHOD}

To prevent contamination of the glass surfaces by skin oils, wear talc-free gloves at all times and handle the plates by their edges. Normal precautions to avoid RNase contamination should be taken (see Introduction: How to Win the Battle with RNase [Green and Sambrook 2019]).

\section{Preparation of Glass Plates}

1. Select a pair of matched glass plates of the appropriate size, two spacers, and a gel comb. Make sure that the spacers and the comb are exactly the same thickness.

Thin gels $(0.3-0.5 \mathrm{~mm})$ give better resolution, do not heat up as much, and are easier to fix and dry than thick $(1 \mathrm{~mm})$ gels are. However, they are more fragile, more difficult to cast, and permit only small amounts of sample to be loaded.

Conventional well-forming combs can be used but frequently result in problems with tearing and deformation of wells, especially at low acrylamide concentrations. They give good results when analyzing RNase protection assays or purifying probes or nucleic acids. Alternatively, a shark's tooth comb can be used. These combs give a flatter, more uniform loading surface than the well-forming combs do, and they reduce the risk of tearing/damage to the gel. They give good results when analyzing sequencing reactions: The close proximity of the lanes allows easier reading of the sequence, but they are prone to allowing leakage of samples between wells.

2. If necessary, remove old silanizing reagent from plates by swabbing them with $\mathrm{KOH} / \mathrm{methanol}$ solution.

3. Wash the plates, spacers, and comb with a warm, dilute solution of dishwashing liquid, and then rinse them thoroughly with tap water, followed by deionized water. Rinse the plates with absolute ethanol to prevent water spots, and allow them to air dry.

The plates must be cleaned meticulously to allow even casting of the gel (i.e., to prevent the formation of air bubbles) and to prevent tearing when the plates are separated after electrophoresis.

4. Treat the inner surface of the smaller (or notched) plate with silanizing solution. To do this, lay the plate horizontally, inner surface facing upward, and pour or spray a small quantity (e.g., a few drops) of silanizing fluid onto the surface of the plate. Spread the silanizing solution evenly over the surface of the plate using several KimWipes. Allow the plate to air dry (1-2 min).

Silanizing agents containing dichlorodimethylsilane are toxic and should therefore be used in a fume hood. Nontoxic alternatives can be used safely on the bench. If pouring a low-percentage acrylamide gel, casting is easier if the back plate is also silanized. If a well-forming comb is to be used, do not silanize the very top of the larger (unnotched) plate because the teeth of the well will collapse if the glass surface is too slippery. 
M.R. Green and J. Sambrook

1
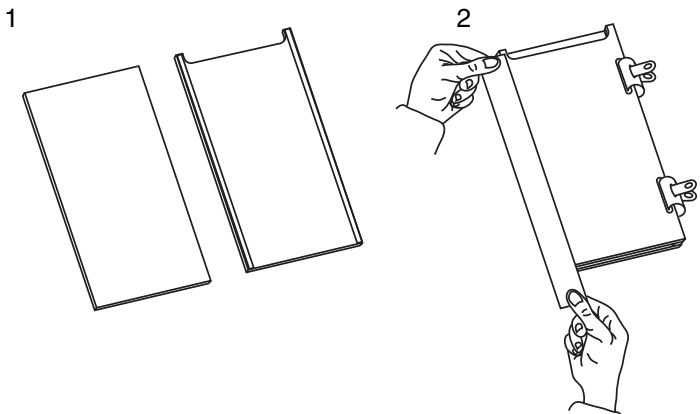

6
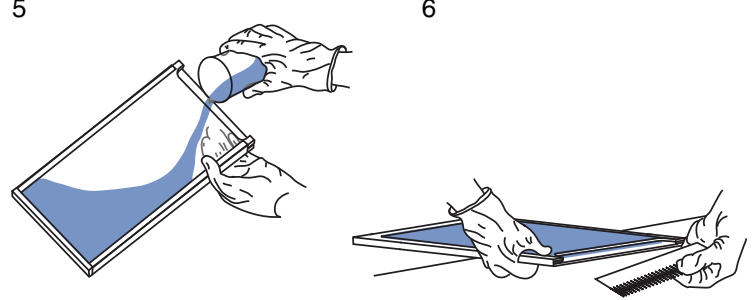

3

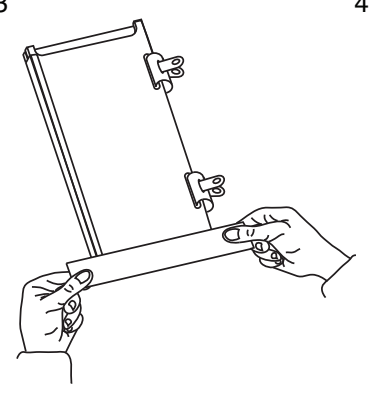

7

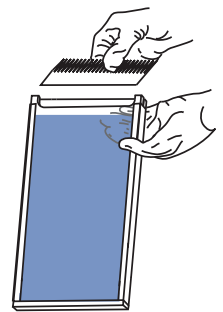

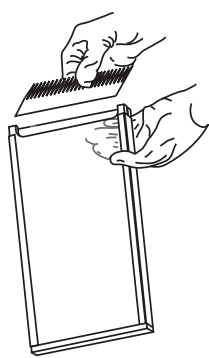

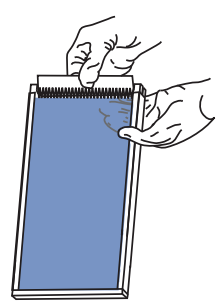

FIGURE 1. Preparation of a polyacrylamide gel.

5. Cover the working area of the bench with plastic-backed protective paper. Lay the larger (unnotched) glass plate on the bench, clean side up, and arrange the spacers on each side of the glass plate (see Fig. 1) so that they are flush with the edges of the plate. Center the smaller (notched) plate, silanized side down, on top of the larger plate. Make sure that the spacers remain in position at the very edges of the two plates.

It is almost impossible to cast the gel without dripping acrylamide solution onto the bench. If using wedgeshaped spacers, place the thicker end of the spacers at the bottom on the plate.

Greasing the entire length of the spacers with a small amount of petroleum jelly will help keep the spacers in position and also help form a seal between the two plates. A small extra dab of petroleum jelly at the corners can also be used to prevent leaking.

6. Clamp the plates together on one side with two or three large bulldog binder clips. Bind the entire length of the other side and the bottom of the plates with gel-sealing tape to make a watertight seal.

The aim is to create a watertight seal between the plates and spacers so that unpolymerized acrylamide solution does not leak out. Most leaks occur at the bottom corners of the plates, thus it is important to take particular care to leave no gaps when folding the tape around the corners. If possible, the corner sections of tape should be folded as "hospital corners."

7. Remove the bulldog clips, and seal the other side of the gel plates with gel-sealing tape.

Casting the Gel

Polyacrylamide gels are chemically cross-linked by the polymerization of acrylamide with a cross-linking agent, usually $N, N^{\prime}$-methylene bisacrylamide. The polymerization initiates by free radical formation usually performed using ammonium persulfate as the initiator and $N, N, N^{\prime}, N^{\prime}$-tetramethylene diamine (TEMED) as the catalyst (Chrambach and Rodbard 1972). The presence of the denaturant urea in the gel prevents the formation of secondary structure and ensures that the RNA molecules migrate through the gel as linear species.

The concentration of acrylamide chosen for the gel depends on the size range of RNAs to be analyzed (see Table 1).

8. In a small beaker or flask, prepare a gel solution containing the desired concentration of acrylamide as specified in Table 2. The volumes given in the table are sufficient for a large, single $40 \times$ $40-\mathrm{cm}$ gel $(100 \mathrm{~mL})$ and can be proportionally adjusted to accommodate smaller or larger gels. For $15 \times 15-\mathrm{cm}$ gels, $\sim 20 \mathrm{~mL}$ is required.

The preparation of the gel must be completed without interruption from this point onward. 
Downloaded from http://cshprotocols.cshlp.org/ on April 26, 2023 - Published by

Electrophoresis of RNA through Polyacrylamide Gels

TABLE 1. Percentage of acrylamide for effective separation of RNAs

\begin{tabular}{lc}
\hline $\begin{array}{l}\text { Percentage acrylamide }(\mathrm{w} / \mathrm{v}) \\
\text { with bisacrylamide at } 1: 20\end{array}$ & Effective range of separation $(\mathrm{bp})$ \\
\hline 3.5 & $1000-2000$ \\
5.0 & $80-500$ \\
8.0 & $60-400$ \\
12.0 & $40-200$ \\
15.0 & $25-150$ \\
20.0 & $6-100$ \\
\hline
\end{tabular}

The values are actually for separation of DNA, but serve as a guide for separation of RNA.

9. Heat the solution for $3 \mathrm{~min}$ in a $37^{\circ} \mathrm{C}$ water bath to help dissolution of the urea. Remove the solution from the water bath, and allow it to cool for $15 \mathrm{~min}$ at room temperature, swirling the mixture from time to time.

Solubilization of urea is an endothermic reaction that proceeds slowly unless an external source of heat is used. Allowing the solution to cool to room temperature before adding ammonium persulfate and TEMED prevents polymerization of the solution from occurring too quickly.

10. Add $500 \mu \mathrm{L}$ of ammonium persulfate to the acrylamide gel mixture, and swirl the solution gently to mix the reagents.

11. Add $50 \mu \mathrm{L}$ of TEMED to the gel mixture, and swirl the solution gently to mix the reagents.

Compared with polyacrylamide gels used to resolve proteins, a massive amount of TEMED is used to cast sequencing gels. The large amount of TEMED ensures that polymerization will occur rapidly and uniformly throughout the large surface area of the gel.

Work as quickly as possible from here onward because the gel solution will polymerize rapidly. Because the rate of polymerization is temperature-dependent, cooling the gel solution allows more time for casting the gel. Experienced gel pourers can often cast two or more $40 \times 40-\mathrm{cm}$ gels from a single gel solution by judicious precooling.

12. Pour the gel solution into the mold directly from the beaker in which it has been prepared (as shown in Fig. 1). Alternatively, draw the solution into a 60-cc syringe, and invert the syringe to expel any air that has entered the barrel. Allow a thin stream of gel solution to flow from the beaker or syringe into the top corner of the gel mold while holding the mold at an $\sim 45^{\circ}$ angle to the horizontal (Fig. 1).

Hold the glass plates at $\sim 45^{\circ}$ and incline to the right by balancing the plates on the bottom right-hand corner. Introduce the beaker or nozzle of the syringe into the notched region of the plates. Slowly and continuously inject the acrylamide solution down the right side of the gel, taking great care not to introduce air bubbles. Fill the bottom right-hand corner first, keeping the air-acrylamide interface smooth. Gradually alter the angle of the gel plates while still injecting so as to fill across the bottom of the gel. Continue injecting down one side of the gel until the acrylamide reaches the top. To avoid producing air bubbles, the solution must flow in a continuous stream (see Troubleshooting).

13. Lay the gel plates horizontally on a support (such as a test tube rack or on a set of four rubber stoppers, one placed under each corner of the plates).

This positioning reduces the hydrostatic pressure at the base of the mold and prevents leaks and bowing of the gel plates.

14. Immediately insert the comb, taking care not to introduce bubbles around the teeth. If using a shark's tooth comb, insert the flat side of the comb $\sim 0.5 \mathrm{~cm}$ into the gel solution. Insert both ends

TABLE 2. Recipes for $8 \mathrm{~m}$ urea denaturing acrylamide gels

\begin{tabular}{|c|c|c|c|c|c|c|c|c|c|}
\hline & $4 \%$ & $5 \%$ & $6 \%$ & $7 \%$ & $8 \%$ & $9 \%$ & $10 \%$ & $11 \%$ & $12 \%$ \\
\hline Acrylamide:bis solution (40\%) & $10 \mathrm{~mL}$ & $12.5 \mathrm{~mL}$ & $15 \mathrm{~mL}$ & $17.5 \mathrm{~mL}$ & $20 \mathrm{~mL}$ & $22.5 \mathrm{~mL}$ & $25 \mathrm{~mL}$ & $27.5 \mathrm{~mL}$ & $30 \mathrm{~mL}$ \\
\hline 10× TBE buffer & $10 \mathrm{~mL}$ & $10 \mathrm{~mL}$ & $10 \mathrm{~mL}$ & $10 \mathrm{~mL}$ & $10 \mathrm{~mL}$ & $10 \mathrm{~mL}$ & $10 \mathrm{~mL}$ & $10 \mathrm{~mL}$ & $10 \mathrm{~mL}$ \\
\hline $\mathrm{H}_{2} \mathrm{O}$ & $44.5 \mathrm{~mL}$ & $42.0 \mathrm{~mL}$ & $39.5 \mathrm{~mL}$ & $37.0 \mathrm{~mL}$ & $34.5 \mathrm{~mL}$ & $32.0 \mathrm{~mL}$ & $29.5 \mathrm{~mL}$ & $27.0 \mathrm{~mL}$ & $24.5 \mathrm{~mL}$ \\
\hline Urea & $48 \mathrm{~g}$ & $48 \mathrm{~g}$ & $48 \mathrm{~g}$ & $48 \mathrm{~g}$ & $48 \mathrm{~g}$ & $48 \mathrm{~g}$ & $48 \mathrm{~g}$ & $48 \mathrm{~g}$ & $48 \mathrm{~g}$ \\
\hline
\end{tabular}

Combine all of the reagents. The volume of the solution will be $\sim 66 \mathrm{~mL}$. Add $\mathrm{H}_{2} \mathrm{O}$ to a final solution volume of $100 \mathrm{~mL}$. 
M.R. Green and J. Sambrook

of the comb into the gel to an equal depth so that the flat surface is level when the gel is standing in a vertical position.

If any air bubbles are visible near the comb, slowly remove the comb from the gel. Wipe the acrylamide solution from the surface of the comb and then slowly reinsert the comb into the gel.

15. Clamp the comb into position using bulldog binder clips. Use the remaining acrylamide/urea solution in the syringe or beaker to form a bead of acrylamide across the top of the gel. Leave the gel to polymerize for 45-60 min at room temperature. A sharp, straight Schlieren line should be visible around the teeth of the comb (or underneath the flat surface of the shark's tooth comb) if polymerization has occurred properly. The gel should be used immediately when used for RNA.

If leakage of the gel solution occurs, see Troubleshooting.

Loading and Running the Gel

16. After the gel has fully polymerized, remove the bulldog clamps and the sealing tape.

17. Stand the plates in the lower buffer reservoir of the vertical electrophoresis apparatus. Clip the plates into the apparatus (place the notched plate against the cathode chamber).

18. Clip the metal plate over the front gel plate.

Not all makes of vertical gel apparatus need this: Many have an integral metal plate positioned against the back (notched) glass plate. Also, it is usually unnecessary for small $15 \times 15-\mathrm{cm}$ gels and may not be a problem with a large RNase protection assay gel that will only be run $\sim 15 \mathrm{~cm}$ (BPB dye front).

The metal plate is used to evenly dissipate heat generated during electrophoresis, thereby minimizing the distortion effects caused by uneven heat transfer and ensuring even running of the samples.

19. Fill the upper and lower reservoirs with $1 \times \mathrm{TBE}$ buffer. Check to make sure that the buffer is not leaking around the glass plates. Carefully remove the comb by wiggling it gently and smoothly. Immediately rinse out urea and fragments of unpolymerized acrylamide from the wells with $1 \times$ TBE and a syringe with a 21-gauge needle.

20. Connect the apparatus to the power supply. Close the safety cover on the upper and lower buffer reservoirs to prevent evaporation of the buffer. Preelectrophorese the gel for 30-45 $\mathrm{min}$ at constant power $(40-50 \mathrm{~W}$ for a $20 \mathrm{~cm} \times 40 \mathrm{~cm}$ long gel).

21. Resuspend the RNA samples in formamide loading buffer. Heat denature the samples for 5-15 min at $70^{\circ} \mathrm{C}$ and then immediately chill on ice to prevent annealing.

If the RNA sample is in the form of a dried precipitate, dissolve it directly in formamide loading buffer. For RNA samples already in solution, mix them with 3 volumes of loading buffer.

The volume of sample loaded should be as small as possible (ideally 1-5 $\mu$ L) to achieve band sharpness. Shark's tooth combs will take up to $3 \mu \mathrm{L}$ in volume, and the wells in a 0.4-mm-thick gel will usually take up to $7 \mu L$.

22. Turn off the power supply, open the top lid, and carefully flush out the wells with $1 \times$ TBE using a syringe, until no urea can be seen floating into the cathode buffer. If using a shark's tooth comb, insert the comb between the glass plates with the teeth facing downward. Immediately load the samples carefully into the bottom of the well. Close the lid on the upper buffer chamber.

Use gel-loading pipette tips that have spatula-shaped tips to make it easier to load the samples between the two plates.

23. Electrophorese at constant power $(40-50 \mathrm{~W}$ for a $20 \times 40-\mathrm{cm}$ long gel) until the bromophenol blue dye (i.e., the faster moving dye) has migrated to the bottom of the gel (see Table 3). For a $5 \%-8 \%$ large sequencing-sized gel, it takes $\sim 1-1.5 \mathrm{~h}$ for the bromophenol blue dye front to reach the bottom of the glass plates.

For the best resolution, run at low voltage $(8 \mathrm{~V} / \mathrm{cm})$. To increase the band sharpness, use a lower voltage for several minutes during the beginning of the electrophoresis. 
Downloaded from http://cshprotocols.cshlp.org/ on April 26, 2023 - Published by

Electrophoresis of RNA through Polyacrylamide Gels

TABLE 3. Expected mobilities of tracking dyes when run with RNA

\begin{tabular}{lcc}
\hline$\%$ Polyacrylamide/urea gel & Bromophenol blue & Xylene cyanol \\
\hline 5 & 35 & 130 \\
6 & 26 & 106 \\
8 & 19 & 76 \\
10 & 12 & 55 \\
12 & 8 & 28 \\
\hline
\end{tabular}

The sizes are given in base pairs for RNA that comigrates with the marker dye.

Detecting RNA in a Denaturing Polyacrylamide Gel

After electrophoresis, the gel can be stained with ethidium bromide (see below) to obtain a photographic record of the separation before electroblotting (Protocol: Transfer and Fixation of Denatured RNA in Polyacrylamide Gels to Membranes by Electrophoretic Transfer [Green and Sambrook 2021a]) and northern hybridization (Protocol: Northern Hybridization [Green and Sambrook 2021b]). Alternatively, gels can be stained with SYBR Green II RNA gel stain.

24. Disassemble the apparatus. Remove the gel plates from the electrophoresis chambers and lay them flat on the bench; be careful, they may be quite hot. If only the front (unnotched) plate has been silanized, place the notched plate uppermost before separating. Insert a stiff piece of plastic between the two plates and carefully pry apart.

The gel should stay attached to the unnotched plate. If the gel is sticking mainly to the backplate (not cleaned well enough!), invert the plates and try again. The gel should remain stuck to one of the glass plates as a support.

25. Lay a piece of Whatman $3 \mathrm{MM}$ paper (or equivalent) that is $2-3 \mathrm{~cm}$ larger than the gel carefully onto the gel surface. If bubbles or wrinkles form, carefully roll these out using a glass rod or test tube. Smooth the paper onto the gel to make the two stick together.

26. Lift one corner of the paper; the gel should stick to it and lift off the glass plate. Remove the paper and gel smoothly in a single motion, and immerse both in a shallow bath of $0.5 \mathrm{mg} / \mathrm{mL}$ ethidium bromide in $1 \times \mathrm{TBE}$ (e.g., $500 \mathrm{~mL}$ of $1 \times \mathrm{TBE}$ and $50 \mu \mathrm{L}$ of $10 \mathrm{mg} / \mathrm{mL}$ ethidium bromide). Stain for $15-45 \mathrm{~min}$.

If the paper refuses to stick to the gel, blot carefully with tissues to remove some of the water and try again. If the gel is torn or wrinkles badly during lifting, gentle washing with a distilled water bottle can be used to get it back into place on the paper surface. If this does not work, float the gel in a bath of distilled water and recover onto wet Whatman paper.

27. Place a sheet of clear plastic wrap over the surface of a UV transilluminator. Lift the gel and paper out of the bath, and lay the gel face down on it. Peel off the Whatman paper, align a transparent ruler with the stained gel, and photograph the gel under UV transillumination.

28. Use the photograph to measure the distance from the loading well to each of the bands of RNA. Plot the $\log _{10}$ of the size of the fragments of RNA against the distance migrated. Use the resulting curve to calculate the sizes of the RNA species detected by blot hybridization.

29. Proceed with immobilization of RNA onto a solid support by electrophoretic transfer (Protocol: Transfer and Fixation of Denatured RNA in Polyacrylamide Gels to Membranes by Electrophoretic Transfer [Green and Sambrook 2021a]).

\section{TROUBLESHOOTING}

Problem (Step 12): Air bubbles are introduced into the gel while pouring.

Solution: To avoid producing air bubbles, the solution must flow in a continuous stream. Consider the following.

- When using a syringe, gradually lower the mold to a horizontal position as it is filled. When the syringe is nearly empty, refill it with gel solution and quickly resume pouring the gel. Take care that 
M.R. Green and J. Sambrook

no air bubbles form and that the solution migrates evenly toward the top of the gel mold. This movement can be facilitated by tilting the gel as described and filling the mold at a constant rate.

- If air bubbles form while pouring the gel, tilt the mold so that the level of the acrylamide solution reaches the level of the bubble. With luck, the air bubble will fuse with the meniscus of the acrylamide solution. If this does not happen spontaneously, try tapping the glass.

- Bubbles in the upper portion of the gel can sometimes be moved by tapping the glass plates or by inserting a thin spacer (bubble hook) and herding the bubbles to a position where they will not interfere with the migration of the RNA samples. The latter solution is possible only when the full width of the gel is not to be used for loading samples.

- Unless the air bubbles can be moved out of the way, the preparation must be done over again. The presence of bubbles is a sign that the gel plates were not cleaned thoroughly before the mold was assembled.

Problem (Step 15): Acrylamide is leaking from the gels.

Solution: Leakage of the gel solution from the bottom of the mold seems to be an inevitable part of a sequencer's life. Several methods are available to prevent leakage.

- Add an extra band of stretchable tape around the bottom of the glass plates. This remedy is also usually effective when older plates with chipped corners are used in the mold.

- Seal the edges of the plates with molten 3\% (w/v) agarose. This approach is messy and requires some artistic talent.

- Insert a plastic spacer into the open space at the bottom of the mold, seal with tape, and then clamp the plates together with bulldog clips. Note that a bulldog clip should be used on the bottom of the gel mold only when this third spacer is in place; otherwise, the gel will vary slightly in thickness, which, in turn, can cause electrophoretic abnormalities and crack the glass plates.

- Seal the bottom of the plate with a strip of filter paper and impregnate with catalyzed acrylamide (Wahls and Kingzette 1988). This is a messy and laborious procedure.

- We recommend that you use whichever of these methods you find to be most reliable with the particular type of gel mold that is available. Do not get discouraged if the first gel leaks. Most firsttime gel pourers have a batting average of about 300 . With practice, a majority of taped gel molds will not leak, batting averages will improve, and it will not generally be necessary to go to great lengths to seal the bottom of the gel.

Formamide Loading Buffer for RNA Gels

Deionized formamide

EDTA (pH 8.0)

$80 \%(\mathrm{w} / \mathrm{v})$

$10 \mathrm{~mm}$

Xylene cyanol FF

$1 \mathrm{mg} / \mathrm{mL}$

Bromophenol blue

$1 \mathrm{mg} / \mathrm{mL}$

Purchase a distilled deionized preparation of formamide and store in small aliquots under nitrogen at $-20^{\circ} \mathrm{C}$.

Alternatively, deionize reagent-grade formamide by stirring on a magnetic stirrer with Dowex XG8 mixed bed resin for $1 \mathrm{~h}$ and filtering it twice through Whatman No. 1 paper. Store deionized formamide in small aliquots under nitrogen at $-70^{\circ} \mathrm{C}$. 


\section{TBE Buffer}

Prepare a $5 \times$ stock solution in $1 \mathrm{~L}$ of $\mathrm{H}_{2} \mathrm{O}$ :

$54 \mathrm{~g}$ of Tris base

$27.5 \mathrm{~g}$ of boric acid

$20 \mathrm{~mL}$ of $0.5 \mathrm{M}$ EDTA (pH 8.0)

The $0.5 \times$ working solution is $45 \mathrm{~mm}$ Tris-borate/ $1 \mathrm{~mm}$ EDTA.

TBE is usually made and stored as a $5 \times$ or $10 \times$ stock solution. The $\mathrm{pH}$ of the concentrated stock buffer should be $\sim 8.3$. Dilute the concentrated stock buffer just before use and make the gel solution and the electrophoresis buffer from the same concentrated stock solution. Some investigators prefer to use more concentrated stock solutions of TBE ( $10 \times$ as opposed to $5 \times)$. However, $5 \times$ stock solution is more stable because the solutes do not precipitate during storage. Passing the $5 \times$ or $10 \times$ buffer stocks through a $0.22-\mu \mathrm{m}$ filter can prevent or delay formation of precipitates.

\section{REFERENCES}

Ansorge W, Labeit S. 1984. Field gradients improve resolution on DNA sequencing gels. J Biochem Biophys Methods 10: 237-243.

Chrambach A, Rodbard D. 1972. Polymerization of polyacrylamide gels: Efficiency and reproducibility as a function of catalyst concentrations. Sep Sci Technol 7: 663-703.

Green MR, Sambrook J. 2019. How to win the battle with RNase. Cold Spring Harb Protoc doi: 10.1101/pdb.top101857.

Green MR, Sambrook J. 2021a. Transfer and fixation of denatured RNA in polyacrylamide gels to membranes by electrophoretic transfer. Cold Spring Harb Protoc doi: 10.1101/pdb.prot101782.

Green MR, Sambrook J. 2021b. Northern hybridization. Cold Spring Harb Protoc doi: 10.1101/pdb.prot101790.
Hengen PN. 1996. Methods and reagents. Pouring sequencing gels the oldfashioned way. Trends Biochem Sci 21: 273-274.

Olsson A, Moks T, Uhlen M, Gaal AB. 1984. Uniformly spaced banding pattern in DNA sequencing gels by use of field-strength gradient. J Biochem Biophys Methods 10: 83-90.

Sanger F, Coulson AR. 1978. The use of thin acrylamide gels for DNA sequencing. FEBS Lett 87: 107-110.

Wahls WP, Kingzette M. 1988. No runs, no drips, no errors: A new technique for sealing polyacrylamide gel electrophoresis apparatus. Biotechniques 6: 308-309. 


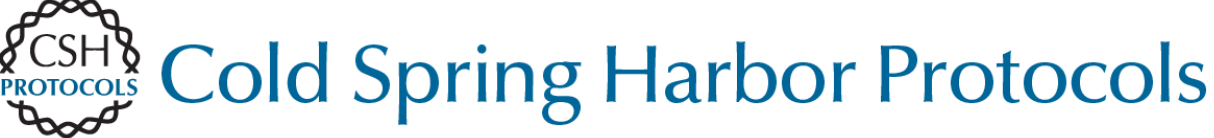

\section{Separation of RNA according to Size: Electrophoresis of RNA through Denaturing Urea Polyacrylamide Gels}

Michael R. Green and Joseph Sambrook

Cold Spring Harb Protoc; doi: 10.1101/pdb.prot101766

\begin{tabular}{cc}
$\begin{array}{c}\text { Email Alerting } \\
\text { Service }\end{array}$ & Receive free email alerts when new articles cite this article - click here. \\
\hline $\begin{array}{c}\text { Subject } \\
\text { Categories }\end{array}$ & Browse articles on similar topics from Cold Spring Harbor Protocols. \\
& Electrophoresis (57 articles) \\
& Electrophoresis of Nucleic Acids (62 articles) \\
& Electrophoresis of Nucleic Acids, general (49 articles) \\
& Electrophoresis of RNA (23 articles) \\
& Electrophoresis, general (130 articles) \\
Molecular Biology, general (1293 articles) & RNA (317 articles) \\
& RNA, general (269 articles) \\
\hline
\end{tabular}

